of chlc roform in small but repeated doses. I have found the first and the last produce the most marked effect. Hyoscyaunus may be given in the form of tincture, from ten to thirty minims three or four times a day; chloroform (from twenty to forty minims) may be placed on the handkerchief, and slowly inhaled every four or six hours. When the cerebral powers appear failing, judicious mental and moral training is certainly of great service. Whilst all undue excitement or over-fatigue should be avoided, much harm may be done by the patient being denied all mental exercise. He should be taught to cultivate the habits of volition, self-direction, and self-control. by due and appropriate exertion of his mind. With regard to organic conditions, special derangements require special medicines, diet, and regimen. Tonics are frequently of service, and my own experience leads me to place more confidence in the oxide of zinc and in the acetate of strychnia than in any other, Much is to be accomplished by alteratives, or such measures as will ensure healthy and abundant secretions. To avoid the possibility of gastro-intestinal disturbance, the most rigid diet should be enforced. With regard to the attacks, they may be often postponed, or put off altogether for a time, by the use of purgatives and alkalis when there is habitual constipation or gastric disturbance with acidity of stomach; and by hyoscyamus or chloroform when the signs of irritable reflective centre are predominant. In other cases the exhibition of a stimulant has the same effect, if there is great exhaustion from over-fatigue or any other cause. Still it is to be feared that there are many cases which will baffle all treatment directed according to our present amount of knowledge; but if we can relieve some, they inspire the hope that, with more advanced pathology, we may be able at some future period to confer the still greater benefit of more successful therapeutics.

Grosvenor-street, 1855.

\section{THREE CALCULI IN THE BLADDER SUC- CESSFULIY REMOVED BY LITHOTRITY.}

BY GRAILY HEWITT, M.B. LoND., SURGICAI REGISTRA TO ST. MART'S FOSPITAL.

I SEND the following successful case of lithotrity for publication, as I think it will be interesting, the instruments em. ployed in the operation being different from those commonly used in lithotrity in this country. I have given the symptoms following the several sittings with minuteness, for I find very few cases of the kind reported in detail :-

Isaac A-_, aged fifty-six, a well-made, healthy-looking man, was admitted into St. Mary's Hospital May 12th, 1855, under the care of Mr. Coulson. His occupation is that of heater in a foundry at Dundivan, near Glasgow, from which place he had come to London to be relieved from the presence of a stone in the bladder, or, at least, from symptoms similar to those experienced by a friend of his who had been operated on in London by Mr. Coulson, the operation performed having been that of lithotrity.

The history of the affection under which he is labouring is as follows:-His health has been generally pretty good. Ten years ago he suffered from pain in the loins, and could not put on his stockings for some time. The urine at that time deposited a good deal of gravel of a brown colour. This condition lasted about three months. Up to two years ago nothing referable to the urinary organs was noticeable. A short time previous to this latter date, he occasionally passed blood in the urine. A few months after the first occurrence of this event, he passed two small stones by the urethra, collectively equal in size to that of a small pea. Subsequently to this period he had laboured under symptoms indicating the presence of a calculus in the bladder-viz., pain before and after the act of micturition, frequency of that act, occasional discharge of blood mixed with urine, \&c. The pain is chiefly felt after the act of micturition, and lasts ten minutes or so. $\mathrm{He}$ is able to get about pretty well; and his general health seems to be unaffected. The stream stops suddenly now and then.

These symptoms indicated the nature of the disease the patient was labouring under; and this opinion was confirmed by sounding the bladder. Mr. Coulson gave it as his opinion, based on an attentive examination with the sound, that there were three stones in the bladder, one of which was considerably larger than the others.

The nature of the operation to be performed had next to be comsidered. Mr. Coulson would have preferred the operation of lithotomy; but the patient did not acquiesce, and expressed his desire to have the same operation performed that his friend had undergone-viz., that of lithotrity. The case was one favourable for lithotrity in many ways. There was no disease of the kidneys; no undue irritability of the bladder; the bladder was capable of holding without diffieulty a tolerable quantity of urine; and the size of the stones was not such as to offer any insuperable difficulties in the way of crushing them. Added to this, the patient's health was good.

The state of the bladder having been ascertained as above, the patient was kept quiet for a few days, and in addition to the ordinary hospital diet, four ounces of gin was ordered to be given daily.

May 16th. - Mr. Coulson used the lithotrite for the first time. The patient was brought into the operating-theatre, placed on a bed, with the pelvis elevated, and resting on a firm cushion, for which purpose a round sofa cushion was found most efficient. 4 catheter was then passed, and the bladder emptied of its fluid contents. A syringe, capable of containing four ouncess of water, was then adjusted to the mouth of the catheter, and the contents of the syringe thrown into the bladder. Mr. Coulson then withdrew the catheter, and introduced a largesized lithotrite. The instruments used were made by Charriere, of Paris, a larger and a smaller one-the same as employed at present by M. Civiale, and capable of being used in three ways, either to crush the stone by the hand or screw, or for the employment of percussion. These instruments were, both on this occasion and at the subsequent sittings, found very effectual in producing the ends desired. The two projections at each side of the handle indicate precisely the position of the fixed part of the lithotrite-viz, the female portion. The male part is easily fixed, when the stone is caught between the blades, by turning a catch which projects against the screw a few turns of a female screw, and thus affords a point of resistance, from which the force used in crushing the stone by means of the screw acts. The lithotrite having been introduced, the larger of the stones was readily seized, and in part broken up. The smaller lithotrite was then introduced, well oiled, and a similar manœurre repeated. The time occupied did not exceed five minutes, a point on the importance of which Mr. Coulson lays considerable stress. No blood followed the use of the instruments. A large catheter was next passed into the bladder, and the water drawn off. The syringe was then brought into requisition again, and the bladder washed ont two or three times. A little warm wine-and-water was administered, and the patient removed to the ward, having'expressed no particular complaint of pain during the operation. No detritus came away during the washing out of the bladder, as was, indeed, the case at the subsequent operations. When removed into the ward, he was ordered to take a draught, containing half a drachm of tincture of hyoscyamus, and one ounce of camphor mixture.

18th.-A tolerable quantity of gritty matter passed to-day and yesterday with the urine, and one piece, evidently a part of the outer shell of a large stone, of a quadrilateral form, and more than half an inch long, was passed to-day. The patient feels comfortable; the bladder is rather irritable, as might be expected. In the evening a slight shivering fit took place.

19th. - A second operation was performed to-day differing in no respect from the first. The operation was effected without producing pain in the true sense of the word, and without any emission of blood. After the operation, wine-and-water and twenty drops of tincture of opium were administered, and ordered to be repeated at bed-time.

The following day, the patient being a little feverish and restless, a dose of saline mixture with a little tincture of hyoscyamus was prescribed three times a day.

$23 \mathrm{rd}$. - The patient is better, but has very little appetite, and does not sleep very well. But few fragments of stone have been passed since the second crushing, and very little gritty detritus. A third operation was performed to-day. It was found that the calculi lay, for the most part, at the right side of the bladder, and towards the pubis, so that the concavity of the lithotrite had to be turned down wards and to the right side in order to seize them. This was, in the following operations, found almost invariably the favourite position of the calculi. One large calculus separated the blades of the lithotrite nearly two inches. No pain was experienced; no pieces came away during the operation. An opiate, with wine, was given as before, and ordered to be repeated at bed-time.

24th. - Last evening a very large piece came away, more than half an inch long and several lines thick, forming a portion of the outer surface of a large stone. During the night the urine passed involuntarily, and there is not perfect control over the orifice of the bladder this morning, this condition being, in all probability, due to the presence of some fragments at the vesical extremity of the urethra. 
26th. - No fragments, only some gritty detritus, have passed the last two days. The urine scalds while passing along the urethra; quantity not great; appetite not good. The patient is able to walk about the ward, although it is not considered advisable to allow him to move about much. To-day the fourth operation was performed.

27th. - The patient is suffering considerably under the irritation of so many angular bodies in the bladder, restless, and uneasy. To have a draught containing half a drachm of tincture of hyoscyamus three times a day; beef jelly.

29th. - The pain has been rather severe the last two days: he has had but little sleep. The bladder is very irritable, and urine is passed sometimes several times in an hour; no grit has passed since the 26 th ; the bowels are a little relaxed. He is sitting up on the side of the bed; face expressive of suffering; the pulse is quiet; there has been no shivering.

30 th. - Last night the patient passed, in succession, several large pieces of stone, the size of peas, the portions passed belonging apparently to the outer part of a large calculus. During the passage through the urethra, the sharp, jagged outline of these fragments gave considerable pain, and the patient helped them along by manipulation outside the urethra. After these pieces had been passed, he became more quiet and slept well. Complains this morning of a little sickness. To have four ounces of wine daily. Mr. Coulson had determined on operating again to-day, but it was considered desirable to wait a few days longer before attempting another operation, the man being very weak and low, and evidently unfit for it. A large catheter was, however, passed, and the bladder thoroughly washed out with tepid water. One or two very small pieces came away.

June 1st.-The patient has slept very well; he feels low and weak. There was a little sickness yesterday; none to-day. The pulse is 90 ; skin moist; tongue red at edges, covered down the middle with a whitish fur. No detritus passed today or yesterday.

2nd. - Several small pieces have come away to-day, varying from the size of a pea to a pin's head. Mr. Coulson ordered the bladder to be washed out again to-day, and a quinine mixture, a dose of which is to be given three times a day.

6th. For the last few nights the urine has passed involuntarily. No fragments have passed since June 2 nd. The patient is very low and weak, and takes very little food. Pulse weak, but not over 90 ; tongue clean ; does not complain of pain, only of excessive weakness ; bowels have acted well from a dose of castor oil. He is, on the whole, better than he has been. Today Mr. Coulson used the lithotrite for the fifth time.

June 8th. - Since the last operation the patient has passed seven or eight large angular fragments at different times, some of them as large as peas. He has more command over the sphincter of the bladder than he had at the last report. Appetite rather improved; pulse 80 . To have chicken for dinner.

9th. - Sixth operation performed. A dose of tincture of opium was given after the operation, as on former occasions, and ordered to be repeated at bed-time.

12th. - No fragments have come away since last sitting; the patient has complete command over the sphineter of the bladder. $\mathrm{He}$ is still low, but better; does not complain of pain ; pulse 70 ; tongue clean.

13th.- Some fragments have been passed to-day. The catheter is used every morning to empty the bladder completely.

16th. - Seventh operation performed to-day. A fragment, of shell-like form, came away in the blades of the lithotrite. 'The patient wishes to be allowed to sleep out of the hospital, which Ar. Coulson accordingly permitted him to do, thinking a change would act beneficially on his general health. The greater part of the fragments have now come away, and there seems to be but little left in the bladder. To come to the hospital for operation on the 20 th.

20th. - The patient is all the better for change of air. The eighth operation was to-day performed. A few pieces have been passed since he left the hospital.

27th. - Ninth operation. Four large pieces passed since the 20 th. The calculi are always met with at the right side of the bladder near the neck.

30th.-Tenth operation. State of patient very much improved; he appears now to be in very good spirits, and has recovered his lost flesh.

July 3rd.--Very few fragments have passed since last opera tion. A little pain before the act of micturition; appetite and spirits excellent. About ten days subsequent to the last report MIr. Coulson sounded the bladder, and could not detect the presence of any fragments. The cure was therefore now com pleted, and the patient was allowed to go home to his friends.
Remarks. - The chief points of interest which presented themselves in the case as above detailed may be briefly stated. The operation was always borne extremely well; no blood ever followed the use of the lithotrite, a sure sign that no injury was done to the bladder; no detritus was generally passed immediately after the operation, the second day after being usually the time at which the fragments came away. At the period when a large number of fragments with angular edges were present in the bladder, a nervous, irritable state was set up, which for a few days occasioned a little uneasiness as to the result of the case. This was, however, happily surmounted. For a time also the sphincter of the bladder was paralyzed, and the urine was passed involuntarily. This condition also disappeared as the bladder was emptied of its irritating contents. The calculi removed were composed of lithate of ammonia, with a little carbonate of lime, the proportion of the latter being, however, very small. The calculi were very hard, as was proved by the fact that the action of the serew was found necessary to produce crushing on all oscasions that the lithotrite was used.

Not the least important fact relating to the treatment of the case was that the inhalation of chloroform was not at any time adopted.

Radnor-place, August, 1855.

\author{
ON A
}

\section{SUCCESSFUL CASE OF OVARIOTOMY.}

\section{By SEAMAN GARRARD, EsQ., M.R.C.S.}

H. R-_, aged twenty, unmarried, a domestic sorvant, slenderly formed, but well-proportioned, light complexion, dark hair and eyes, and having the appearance of a person seven or eight months advanced in pregnancy, stated that she had always enjoyed good health; that in the month of October last she and her friends observed that she had become stouter than usual. It was, however, not attributed to ill-health, but to the supposed beneficial effects of a change of air and residence. Shortly afterwards, she was suddenly seized with violent pain in the right hypogastric region after some unusual bodily exertion.

The surgeon of the family was consulted, and her pain was relieved; but from this time she rapidly increased in size, and was in consequence obliged to leave her situation. The catamenia first appeared at the age of thirteen; and she has menstruated regularly ever since. Upon examination of the abdomen a soft and fluctuating tumour was found, occupying almost its entire front, with however a greater prominence and inclination towards the right side. Percussion every where yielded a dull sound, except in the upper part of the epigastric and left hypogastric regions, where resonance was very distinct, showing the boundary of the tumour in that direction, and affording, in addition to the inclination of the enlargement to the right side, reason to diagnose a large encysted tumour of the right ovary. The uterus was perfectly healthy. There was no bulging of the tumour to be felt between the neck of the uterus and either side or back of the pelvis; but anteriorly between the neck of the uterus and the bladder a kind of distended fulness could be discovered, but which gave no fluctuation on percussing the front of the abdomen.

On the 25th of April last I performed the operation of ovariotomy, by an incision through the abdominal parietes, extending from just below the umbilicus to the pubis. The cyst was thus exposed at its lower part, and proved to be binocular; the two cells perfectly divided by a nearly perpendicular septum. The larger cell lying anteriorly, and oceupying the front of the abdomen; the smaller one, the back and lower part. It was the lower part of this posterior cell which was indistinctly felt between the bladder and neck of the uterus, but which was so covered by the anterior cell that no fluctuation could be conveyed on striking the abdomen externally. These cells were then successively tapped, and twenty two pints of fluid of the usual character drawn off. The fluid from the posterior cell was of a darker colour than the other. The collapsed cyst was then attempted to be drawn forth, but it was found to be immovable from adhesions. I then introduced my hand, and found that the cyst was adherent anteriorly to the parietes of the abdomen throughout almost its whole surface. These adhesions, however, readily yielded to the hand, giving a sensation very similar to that of separating an adherent placenta. Portions of omentum were then found adherent, but with a little care were readily peeled off. On trying to separate the cyst from the right 